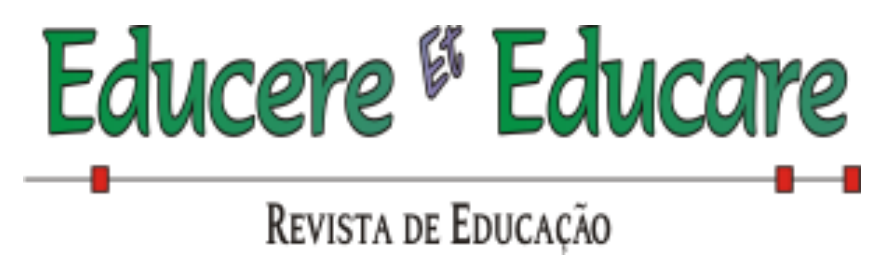

Programa de Pós-Graduação em Educação - Universidade Estadual do Oeste do Paraná

\title{
A ÉTICA NO ENSINO DE QUIMICA: UM OLHAR A PARTIR DAS PUBLICAÇÕES NO ENCONTRO NACIONAL DE ENSINO DE QUÍMICA E NAS REVISTAS QUÍMICA NOVA E QUíMICA NOVA NA ESCOLA
}

Me. Iara Lucia Lazzarin

Dr. Vilmar Malacarne

Universidade Estadual do Oeste do Paraná

RESUMO: Este trabalho tem como objetivo apresentar como o tema ética está sendo tratado em publicações da área da Educação em Química. Realizamos um levantamento em uma amostra de publicações no Encontro Nacional de Ensino de Química e nas Revistas: Química Nova e Química Nova na Escola, no período compreendido entre 2008 a 2013. A coleta de dados foi realizada mediante o uso da ferramenta automática de busca, com a utilização das palavras-chave, "ética”, "moral”, "valor", "respeito", "comportamento" e "caráter". As considerações finais apontam para a necessidade de inserção de maiores discussões sobre a ética na formação inicial, na educação escolar e nas pesquisas na área de Química para que possamos superar as dificuldades pedagógicas e proporcionar uma atmosfera de reflexão sobre a ética envolvida nos conceitos da Química.

PALAVRAS-CHAVE: Ética; Ensino de Química; Formação de Professores

\section{ETHICS IN CHEMISTRY TEACHING: A VIEW FROM PUBLICATIONS IN THE NATIONAL MEETING FOR CHEMISTRY EDUCATION AND THE JOURNALS QUÍMICA NOVA AND QUÍMICA NOVA NA ESCOLA}

\begin{abstract}
This paper has for goal to present how ethics is beeing approached on publications in the chemistry education field. We have made a survey on several publications on the National Meeting for Chemistry Education and also on the journals: Química Nova and Quimica Nova na Escola, between the years 2008 to 2013. The data collection was done by using the auto-search tool, applying the keywords, "ethics", "moral",
\end{abstract}

"value", "respect", "behavior" and "character". The final considerations show the need for larger discussions about ethics on the initial formation, at school and over researches at the Field of chemistry so we can overcome the pedagogic difficulties and provide an atmosphere of reflection about ethics concerning the chemistry concepts.

KEYWORDS: Ethics; Chemistry Teaching; Teacher Training 


\section{Educere "Educare \\ Revista de EduCAČ̃̃o}

Programa de Pós-Graduação em Educação - Universidade Estadual do Oeste do Paraná

\section{INTRODUÇÃO}

A ética está inserida no cotidiano das pessoas nos diferentes arranjos sociais. Segundo Cortina e Martinez (2005, p.03), "[...] a palavra ética vem do grego ethos, originalmente tinha o sentido de "morada", "lugar em que se vive" e posteriormente significou "caráter", "modo de ser" que se vai adquirindo durante a vida [...]". Nesse sentido, a ética possui elementos de compreensão que devem ser estendidos ao longo da existência de cada indivíduo.

Ao refletimos sobre o processo de formação deste individuo, não deveria ser elementar supor que nos bancos escolares houvessem discussões sobre ética? Porém, o cenário educacional não aponta para a ocorrência corriqueira de tal prática. E, quando expandimos o pensamento até a área das Ciências, as incidências de discussões tornam-se mais diminutas ainda.

Se voltarmos nosso olhar para a formação do profissional da área de Educação em Química, o tema ética atinge questões que precisam ser ainda melhor discutidas, pois, como na maioria das áreas, está, ou deveria, estar inserido tanto durante a formação inicial quanto na formação continuada e em toda esfera educacional, com o intuito de propiciar uma formação mais cidadã, crítica e reflexiva.

Nesta perspectiva, neste estudo, apresentaremos uma análise sobre de que maneira o tema ética está sendo tratado em publicações da área da Educação em Química. Para tanto, algumas reflexões necessitam de maiores debates: Quais princípios regem a ética no Ensino de Ciências em geral? E na Química? A ética tem contribuído ou retardado o desenvolvimento científico? Cabe a alguma disciplina nos cursos universitários em específico discutir sobre ética? Ou todas as disciplinas da formação inicial deveriam discuti-la? 


\title{
Educere Educare \\ ReVISTA DE EduCACÃo
}

Programa de Pós-Graduação em Educação - Universidade Estadual do Oeste do Paraná

As Diretrizes Curriculares Nacionais para os Cursos de Química, entre outras indicações, estabelecem que durante a formação o Químico Licenciado deve:

\begin{abstract}
Possuir capacidade critica para analisar de maneira conveniente os seus próprios conhecimentos; assimilar os novos conhecimentos científicos e/ou educacionais e refletir sobre o comportamento ético que a sociedade espera de sua atuação e de suas relações com o contexto cultural, socioeconômico e político. (Brasil, 1999, p.06)
\end{abstract}

A reflexão sobre a ética envolvida nas relações entre o conteúdo da disciplina de Química e a sociedade devem estar inseridas, assim, diretamente no cotidiano dos profissionais da Química. De acordo com Torresi, Pardini e Ferreira (2008, p.197), “[...] a ética deve reger todos os campos de atividades humanas, e por isso tem diversas variações, como ética na ciência, política, economia, negócios, química, medicina e publicações científicas”.

Embora a ética esteja tão enraizada nas sociedades, como é possivel reestruturar os conceitos e significados sobre ética, discuti-los e aprimora-los no âmbito do Ensino de Ciências, sem que pareça apenas um assunto filosófico? Deve, este, ser um tema que deva ser apenas discutido em disciplinas das ciências humanas?

Nesse aspecto, como verificamos na Lei 9.394/96-Lei de Diretrizes e Bases da Educação Nacional (Brasil, 1996, p.29) esta aponta como uma das finalidades do Ensino Médio: “[...] o aprimoramento do educando como pessoa humana, incluindo a formação ética e o desenvolvimento da autonomia intelectual e do pensamento crítico [...]". Corroborando com a orientação pedagógica escolar, os Parâmetros Curriculares Nacionais (Ensino Médio) (Brasil, 2000, p.08), na Parte IV- Ciências Humanas e suas Tecnologias retomam o os princípios propostos pela Comissão Internacional sobre Educação para o Século XXI, da UNESCO, baseados nos saberes: aprender a conhecer, aprender a fazer, aprender a conviver e no aprender a ser. No que tange o aprender ser estabelece "[...] a ética 


\section{Educere Educare \\ ReVISTA DE EduCACÃ̃o}

Programa de Pós-Graduação em Educação - Universidade Estadual do Oeste do Paraná

da identidade, exigida pelo desafio de uma educação voltada para a constituição de identidades responsáveis e solidárias, compromissadas com a inserção em seu tempo e em seu espaço, pressupõe o aprender a ser [...]".

A partir destes indicativos que orientam a educação, um dos modos que podemos verificar se tais direcionamentos estão sendo de fato aplicados na área de Ensino de Químicas é por meio da quantidade de publicações nesse campo educacional. Pesquisas anteriormente realizadas por Razera e Nardi (2006, p.53) destacam que: "[...] amostras de publicações recentes sobre o ensino de Ciências, em periódicos científicos da área, revela que questões sobre ética e desenvolvimento moral têm sido negligenciadas nas pesquisas em Educação em Ciências [..]".

Nesta mesma perspectiva, realizamos um levantamento que buscasse, nos últimos cinco anos, se esse panorama mudou para a área de Química e quais as discussões que estão sendo efetivadas sobre a ética nos veículos da educação em Química.

\section{Percurso Metodológico da Pesquisa}

Com o intuito de mapear como o tema ética esta sendo apresentado no Ensino de Química, realizamos uma consulta aos periódicos Química Nova e Química Nova na Escola, duas revistas com versões on-line e com tradição na área de Química. Nossos olhares também se voltaram ao principal evento da área de educação em Química, o Encontro Nacional de Ensino de Química (ENEQ). Para a pesquisa empregamos a seguinte metodologia:

I) Seleção das revistas: para a análise foram selecionadas as revistas que são publicações da Sociedade Brasileira de Química. As revistas Química Nova e 


\section{Educere Educare \\ Revista de EduCAC̄̃̃o}

Programa de Pós-Graduação em Educação - Universidade Estadual do Oeste do Paraná

Química Nova na Escola estão classificadas como B2 na área de Educação (possuem também outros ranquiamentos em outras áreas) pelo sistema de avaliação Qualis da CAPES (Coordenação de Aperfeiçoamento de Pessoal de Nivel Superior). As duas revistas nacionais possuem disponibilidade de versões on-line e são gratuitas. Para a consulta nas páginas das revistas, no período compreendido entre 2008 e 2013, utilizamos a ferramenta de localização automática do aplicativo Adobe® Acrobat Reader versão 10.0. Foram pesquisados os titulos, resumos e palavras-chave de todas as edições, utilizando como busca as palavras "ética", "moral", "valor", "respeito", "comportamento" e "caráter".

II) Levantamento dos trabalhos apresentados no ENEQ: O Encontro Nacional de Ensino de Química (ENEQ) é um evento bianual organizado pela Divisão de Ensino de Química da Sociedade Brasileira de Química (SBQ) com a parceria de Universidades e demais entidades envolvidas. Para os objetivos desta pesquisa, realizamos uma busca nos anais dos XIV, XV E XVI Encontro Nacional de Ensino de Química, com o objetivo de selecionar os trabalhos referentes as discussões sobre ética no ensino de Química. O levantamento dos trabalhos expostos no ENEQ abrangeu o período compreendido entre 2008 e 2013; efetuamos a busca de modo similar à busca dos periódicos, utilizado o mesmo dispositivo aplicado na pesquisa aos periódicos, as palavras chave também foram as mesmas utilizadas na pesquisa às revistas.

III) Leitura e análise dos artigos encontrados pela ferramenta de busca: após a leitura inicial, realizamos a leitura e análise dos artigos completos, com o intuito de verificar de que forma os temas sobre a ética estavam sendo abordados.

\section{Tímidas Discussões Sobre a Ética no Ensino de Química}

O levantamento realizado no período entre 2008 e 2013 tanto nas publicações das Revistas Química Nova, Química Nova na Escola e no ENEQ 


\section{Educere "Educare \\ Revista de EduCAC̄̃̃o}

Programa de Pós-Graduação em Educação - Universidade Estadual do Oeste do Paraná

apontam que as discussões sobre ética no Ensino de Química estão caminhando a passos lentos.

Na Revista Química Nova, foi feita a busca em 58 edições, compreendida entre as publicações dos volumes 31 ao 36, totalizando 2097 artigos. Encontramos, com a busca pela palavra "ética", apenas três editoriais sobre o tema, dois assinados pelos editores da revista e o último por um convidado, publicados nos anos de 2008, 2011 e 2013. Nenhum artigo foi encontrado utilizando como busca as palavras: "ética", "moral", "valor", "respeito", “comportamento" ou "caráter".

Os editoriais da Revista Química Nova explicitam a preocupação da revista com a ética voltada às pesquisas na área de química, em 2008 o editorial escrito por Torresi, Pardini e Ferreira (2008, p.197) apresenta as normas de publicação, as citações, referências e a participação efetiva dos autores na escrita dos artigos. Em 2011, o editorial de autoria Torresi, Pardini e Ferreira (2011, p.1489) aborda a questão da ética nas publicações científicas, indicando que o tema seria discutido na $35^{\mathrm{a}}$ Reunião Anual da Sociedade Brasileira de Química, que teria como título: "Responsabilidade, Ética e Progresso Social". Ainda, os editores abordam o trabalho chamado de Código Boas Práticas, desenvolvido pela Fundação de Amparo à Pesquisa do Estado de São Paulo, e que estabelece diretrizes éticas ao pesquisador. O editorial escrito pelo convidado Rocha Filho (2013, p.357), faz um apanhado sobre o desenvolvimento de pesquisas científicas no Brasil, apontando para o fato de que estas devam ser produzidas com ética e integridade. Aponta também para a participação da Coordenação de Aperfeiçoamento de Pessoal de Nível Superior, do Conselho Nacional de Desenvolvimento Científico e Tecnológico e da Revista Química Nova como incentivadores de tal comportamento ético.

Do total de 24 edições da Revista Química Nova na Escola, no período de tempo compreendido por esta pesquisa, entre os Volumes 27 e 35, totalizando Revista Educere Et Educare, Vol. 13, N. 27, jan./abr. 2018. Ahead of Print. 


\section{Educere "Educare \\ Revista de EduCAČ̃̃o}

Programa de Pós-Graduação em Educação - Universidade Estadual do Oeste do Paraná

276 artigos, encontramos publicações sobre o tema somente no ano de 2010, onde foram encontrados dois artigos com a palavra "ética" e um artigo com a palavra "valor".

O primeiro artigo encontrado na busca pela palavra "ética", os autores Sá, Vicentin e Carvalho (2010, p.09-13), abordam a questão da ética e da formação do cidadão durante as aulas do $1^{\circ}$ ano do Ensino Médio, apontando para a possibilidade do emprego das artes cênicas e da história para o aprendizado de conteúdos da disciplina de Química. Por meio da interdisciplinaridade, os professores de Química, História e Artes, juntamente com os alunos, desenvolveram peças de teatro, cujo tema central era abordado por personagens da história das Ciências onde, a partir de pesquisas, os alunos puderam contextualizar e compreender o processo de desenvolvimento de um conceito científico. Na mesma atividade foram realizados debates referentes aos temas estudados, os acontecimentos que levaram ao surgimento daqueles conceitos, a contribuição da Ciência ao avanço tecnológico e a qualidade de vida. Tais atividades teriam permitido o posicionamento dos alunos perante os acontecimentos, tornando-os agentes de construção do próprio conhecimento.

No segundo artigo, encontrado com a busca pela palavra "ética", o autor Oliveira (2010, p.227-232), discorre, entre outras coisas, sobre o Ensino de Química, Física e Biologia no Ensino Médio, apontando para o desinteresse dos alunos por tais disciplinas e, também, sobre o ensino voltado às verdades absolutas, com ênfase em formulações matemáticas e memorização de enunciados. O texto ainda estabelece uma interface do Ensino de Ciências com a ética, sob o ponto de vista científico, apresentando a ética Kantiana, os juízos do empirismo e do racionalismo. O autor proporciona exemplos de conteúdos das disciplinas de Física, Química e Biologia que poderiam tratar de assuntos éticos envolvidos nessas áreas do conhecimento. 


\section{Educere "Educare \\ Revista de EduCAČ̃̃o}

Programa de Pós-Graduação em Educação - Universidade Estadual do Oeste do Paraná

No terceiro artigo elencado, este encontrado com a busca pela palavra "valor", os autores Ribeiro, Maia e Wartha (2010, p.169-175) apresentam um relato de experiência a partir de uma proposta pedagógica no Ensino de Química realizada com alunos do $3^{\circ}$ ano do Ensino Médio. Nesta abordam o uso de sabões e detergentes e a degradação do Rio Cachoeira na Bahia. Os autores envolvem, em suas discussões, questões específicas do conteúdo de química, como cálculos estequiométricos, reações química, propriedades físicas, assim como as discussões sobre apontamentos sociocientíficas e ambientais envolvidas no uso consciente de sabões, na redução no consumo de água, nas ligações corretas da rede de esgoto, enfim o repensar sobre atitudes e valores relacionados à cidadania no cotidiano.

Em relação aos Encontros Nacionais de Ensino de Química, o XIV ENEQ, sediado na Universidade Federal do Paraná no ano de 2008, apresentou nos anais dados que apontaram o total de 462 trabalhos apresentados, divididos entre resumos e trabalhos completos em áreas variadas do Ensino de Química. A concentração dos trabalhos foi na área de Ensino e Aprendizagem com 150 trabalhos, Formação de professores com 97 e Experimentação no Ensino com 51 trabalhos. As áreas com menores quantidades de estudo foram: Linguagem e Cognição com 10 trabalhos, História e Filosofia da Ciência com 17 e Ensino e Cultura também com 17 trabalhos.

Evento realizado com sede na Universidade de Brasilia, o XV ENEQ 2010 revelou em seus anais, que foram apresentados 824 trabalhos em áreas distintas, a maior quantidade foi na área de Ensino e Aprendizagem com 158 trabalhos, em segundo lugar a Formação de professores com 96 e Materiais Didáticos com 63 trabalhos. As áreas com menores quantidades de estudo foram: Ensino e Cultura com 11 trabalhos, 17 trabalhos em Ensino em Espaços Não-Formais e em História e Filosofia da Ciência com 20 trabalhos. 


\section{Educere "Educare \\ Revista de EduCAČ̃̃o}

Programa de Pós-Graduação em Educação - Universidade Estadual do Oeste do Paraná

No XVI ENEQ, realizado com parceira da Universidade Federal da Bahia, foram apresentados 972 trabalhos em campos diversos. A concentração se deu nas áreas Ensino e Aprendizagem com 354 trabalhos, Formação de professores com 215 e Experimentação no Ensino com 180 trabalhos. As áreas com diminutas temáticas de estudo foram: Políticas Educacionais com 3 trabalhos, História, Filosofia e Sociologia da Ciência no Ensino de Química com 16 trabalhos e História da Química e Filosofia da Química no Ensino de Química com 28 trabalhos.

Como ferramenta de busca nestes eventos, novamente utilizamos a ferramenta de localização automática do aplicativo Adobe ${ }^{\circledR}$ Acrobat Reader versão 10.0. As palavras chaves nos trabalhos publicados também foram as mesmas das revistas: "ética", "moral", "respeito", "valor", “comportamento" e ou "caráter". Para nossa surpresa, o buscador não nos apontou nenhum trabalho que estivesse ligado a questão da ética no Ensino de Química nas três edições do evento.

A partir do levantamento dos trabalhos, podemos destacar o número ascendente de trabalhos nas três edições avaliadas do ENEQ, verificamos nos três eventos a predominância de trabalhos com temas voltados ao "Ensino e Aprendizagem" e "Formação de Professores", ainda constatamos um número reduzido de trabalhos voltados a "Filosofia e História da Química". Para os autores Razera e Nardi:

As pesquisas em ensino de Ciências tendem cada vez mais a ampliar o foco dos problemas investigados, mas ainda assim parecem limitadas a algumas temáticas, excluindo outras que merecem um olhar mais atento dos pesquisadores da área. Pesquisas que abordam problemas sobre aspectos cognitivos referentes à construção e ao desenvolvimento do conhecimento, por exemplo, estão presentes em número significativo nos trabalhos publicados. Por outro lado, aspectos não menos importantes são negligenciados ou omitidos no conjunto das investigações da área, como ocorre com os problemas inerentes ou correlatos aos processos de construção e evolução da moral no aluno: uma das questões básicas da ética. (Razera; Nardi, 2006, p.53) 


\section{Educere Educare \\ ReVISTA DE EduCACÃ̃o}

Programa de Pós-Graduação em Educação - Universidade Estadual do Oeste do Paraná

Portanto, mesmo tratando de pesquisas diferentes, encontramos resultados muito similares a pesquisa de Razera e Nardi (2006), o que pode nos indicar que as pesquisas desenvolvidas continuam não priorizando os aspectos éticos e morais na área das Ciências Naturais.

\section{A Ética no Ensino de Química}

Com o intuito de compreender aspectos sobre a ética, Cortina e Martinez (2005, p.09) descrevem que a ética hoje aborda os conceitos que a filosofia grega já vinha discutindo há muito tempo: "[...] a Ética é um tipo de saber normativo, isto é, um saber que pretende orientar as ações dos seres humanos [...]".

Entretanto, realmente são necessárias as discussões sobre ética no Ensino de Ciências? A aprendizagem torna-se mais enriquecedora quando os conteúdos são voltados a história, ao contexto em que tal conteúdo foi "descoberto", no estabelecimento de questionamentos éticos em uma problematização relacionada ao conteúdo científico em que está sendo estudado. Para o autor Oliveira:

Tal como na ciência não cabe desvelar verdades ocultas, no campo da ética, estas também não foram estabelecidas para todo o sempre, de sorte que a problematização, em ambos os casos, é crucial. Assim sendo, assumir uma perspectiva problematizadora é dar um passo importante na constituição de interfaces entre o ensino científico e a abordagem de questões éticas na escola. (OLIVEIRA, 2010, p.230)

Mas, como é possivel inserir o tema ética nas disciplinas das ciências naturais? O Ensino de Ciências está inserido na educação escolar desde a educação infantil até o término do Ensino Médio, assistido por uma série de regulamentações que deveriam garantir a formação mínima dos cidadãos nesta área. De acordo com Nardi:

A institucionalização da ciência em nível escolar se dá através do estabelecimento de vários mecanismos: legislações e normas, posteriormente assumidas em caráter oficial pelos governos através da 


\section{Educere "Educare \\ ReVISTA DE EduCAC̄̃o \\ Programa de Pós-Graduação em Educação - Universidade Estadual do Oeste do Paraná}

determinação de parâmetros, diretrizes curriculares, currículos mínimos; a criação de cursos de formação de professores específicos para o ensino da ciência em suas diversas ramificações ou modalidades; e a criação de outras instâncias paralelas - geralmente chamadas de não-formais como centros de ciências, museus e revistas de divulgação.(NARDI, 2007, p.359)

Ao compreender que as Ciências Naturais assumem o papel de despertar a curiosidade dos alunos para a descoberta do mundo científico, assuntos envolvendo a ética não podem estar desvinculado de tal aprendizado. O professor, por exemplo, ao apresentar um conceito, pode incentivar os alunos a discutirem as motivações, o contexto, as necessidades, a história, os interesses e os acontecimentos que conduziram tal pesquisa. Ao fazer isso, estará discutindo questões éticas inseridas na educação científica.

Uma pesquisa realizada por Lins et al (2007) com alunos e professores de um curso de Ensino de Médio de Formação de Professores, no Rio de Janeiro, concluiu que:

Os resultados da categorização feita a partir da análise dos dados obtidos nesta pesquisa qualitativa apontam uma falta de informação sobre Educação Moral/Ética de maneira geral. Notou-se o desconhecimento de conceitos básicos desta área do saber... No que diz respeito aos professores, as observações revelam que eles têm uma grande dificuldade para lidar com o tema, tanto conceitualmente como do ponto de vista didático. (LINS at al, 2007, p.274)

Na mesma perspectiva, ao pensar o Ensino de Química, Oliveira (2010, p.231) aponta, como uma interface possivel entre o Ensino de Ciências e a Ética, especificamente para a Química, temas que poderiam ser trabalhados ao longo da disciplina, como as questões ambientais, quando forem abordados conteúdos como radioatividade, polímeros, o uso do uso de agrotóxicos e o consumo de medicamentos sem receita médica. O autor estimula a discussão sobre o tema ética mesmo quando relacionado a conceitos mais específicos. Nos diz ele: 


\section{Educere Educare \\ ReVISTA DE EduCACÃ̃o}

Programa de Pós-Graduação em Educação - Universidade Estadual do Oeste do Paraná

de certas posturas assumidas pelos cientistas. Sabemos, por exemplo, que Dalton se recusou a admitir a existência das moléculas, preferindo manter a terminologia "átomos compostos". Segundo Papp e Prélat (1950, p. 128), a recusa não foi simplesmente uma questão de nomenclatura, mas "a ideia de um átomo composto por átomos iguais entre si repugnava a Dalton". Uma estratégia pedagógica cabivel nesse caso é perguntar: até que ponto os valores morais e religiosos do químico inglês não foram um obstáculo à aceitação das contribuições trazidas por Avogadro? Dalton era adepto da doutrina Quaker, religião cristã fundada no século XVII e marcada pela austeridade moral, de modo que isso provavelmente influiu sobre suas ideias no campo científico. (OLIVEIRA, 2010, p.231)

Nessa perspectiva da inclusão do tema ética em conceitos específicos da disciplina de Química, que Sá, Vicentin e Carvalho (2010, p.11), apontam que a Química deve ser entendida como construção humana, influenciada por aspectos politicos, sociais e econômicos, com estreita relação em suas aplicações tecnológicas, questões ambientais e éticas.

Porém, muitos avanços se fazem necessário nesse âmbito, um indício de que o tema ética no Ensino de Química necessita de maiores discussões são as poucas referências bibliográficas que se encontra no cenário educacional brasileiro. O tema ainda é pouco tratado, ficando quase a margem dos temas abordados. Há priorização de temas específicos da área de Química, tais como Ensino e Aprendizagem, Formação de Professores e Experimentação, que são temas tão importantes quanto a formação ética e moral dos estudantes, porém este é pouco abordado. Nesta perspectiva é que se insere nossa defesa: que o tema da ética seja tratado dentro dos conteúdos curriculares da disciplina de Química e na formação inicial dos professores de Química como uma forma deste se tornar visivel também quando publicação quer em revistas ou em eventos importantes, discutam o papel da Química na sociedade contemporânea. 


\section{Educere "Educare \\ ReVISTA DE EduCACÃ̃o}

Programa de Pós-Graduação em Educação - Universidade Estadual do Oeste do Paraná

\section{CONSIDERAÇÕES FINAIS}

A ética pode ser definida, segundo Gallo (2003, p.54), como a parte da filosofia que se dedica a pensar as ações humanas e os seus fundamentos. Porém não é um tema isolado dentro da educação, está envolvido diretamente no cotidiano escolar dentro de todas as áreas do conhecimento. Os Parâmetros Curriculares Nacionais (1999, p.39) apontam a ética como um dos temas transversais, cabendo à escola proporcionar ao aluno "[...]o desenvolvimento de capacidades, como as de relação interpessoal, as cognitivas, as afetivas, as motoras, as éticas, as estéticas de inserção social, torna-se possível mediante o processo de construção e reconstrução de conhecimentos [...]". Não especificando que uma disciplina em específico seja responsável por isso.

Nesta direção, faz-se necessário uma formação educacional que possibilite formar alunos cidadãos, capazes de tomar decisões, com atitudes coerentes com os valores morais da sociedade. Para Pradel e Dáu, é necessário reflexões sobre a ética:

Mesmo para um tema que se denomina como transversal, é necessário que seja refletido em uma base curricular, neste caso voltada ao trabalho com valores e, portanto, ligada à formação humanista, que conjuga conhecimento e pensamento ético, refletido em ações. (PRAU; DÁU, 2009, p.525-526)

Especificamente para o Ensino de Química, onde muitas vezes os conceitos são apresentados como verdades absolutas, se faz necessária a discussão sobre a ética atrelados aos conceitos científicos. Para Chassot:

As diferentes análises que têm sido feitas sobre o ensino de Química exigem, cada vez mais, um ensino em Química seja um suporte para se fazer educação. Isso quer significar que não basta que se faça a transmissão de conhecimentos químicos (alguns de discutivel valor para a formação científica do cidadão), mas é importante que esses conhecimentos sejam instrumentos para melhor se fazer educação. (CHASSOT, 2004, p. 44) 


\section{Educere Educare \\ ReVISTA DE EduCACÃ̃o}

Programa de Pós-Graduação em Educação - Universidade Estadual do Oeste do Paraná

As publicações na área da Educação em Química provavelmente refletem o que ocorre no ensino. No levantamento realizado por nossa pesquisa, entre os anos de 2008 e 2013, a busca nos artigos publicados nas Revistas Química Nova e Química Nova na Escola, utilizando palavras centrais de busca, encontramos um total de somente 3 artigos relacionados ao tema ética. De maneira análoga a pesquisa nas revistas, a busca nas publicações das três últimas edições do Encontro Nacional de Ensino de Química (XIV, XV e XVI), com a busca pelas palavras-chave não encontramos nenhuma pesquisa ou trabalho referente ao tema.

Conforme percebemos na pesquisa realizada, apesar das legislações estabelecerem que durante a educação formal, o estudante tenha uma formação como cidadão, com discussões sobre temáticas como ética, moral e formação de cidadãos, não há evidências, pelo menos na pesquisa realizada, que apontem para tal. Não se percebe com clareza que o sistema educacional esteja se articulando para tal, pelo contrário, o que se percebe são sistemas inchados e engessados em um ambiente totalmente desfavorável ao debate e discussão sobre temas tão relevantes.

Tomando-se a pesquisa que realizamos podemos verificar que existe um amplo campo a ser explorado. As discussões sobre a ética voltada para o Ensino de Química ainda são diminutas em relação aos temas específicos tratados na Educação em Química, apontando assim para a necessidade de que incentivos sejam dados para que tal realidade se modifique, modificando assim, por consequência, a relação deste profissional com sua própria atitude em relação ao seu objeto de estudo. 


\section{Educere "Educare \\ ReVISTA DE EduCACÃ̃o}

Programa de Pós-Graduação em Educação - Universidade Estadual do Oeste do Paraná

\section{REFERÊNCIAS BIBLIOGRÁFICAS}

BRASIL. Diretrizes Curriculares Nacionais para a Formação de Professores da Educação Básica, em nível superior, curso de licenciatura, de graduação plena. Disponivel em: $<$ http:// portal.mec.gov.br/index.php?option=com_content\&id=12991:diretrizescurriculares-cursos-de-graduacao>. Acesso em: 06 mar 2014.

.Secretaria de Educação Média e Tecnologia. Parâmetros Curriculares Nacionais:Ensino Médio. Disponível em $<$ http://portal.mec.gov.br/seb/arquivos/pdf/cienciah.pdf $>$. Acesso em 15 mar 2014.

.Lei de Diretrizes e Bases da Educação Nacional. Disponível em <http://portal.mec.gov.br/arquivos/pdf/ldb.pdf>. Acesso em 15 mar 2014.

.Diretrizes Curriculares Nacionais para os Cursos de Química. Disponível em: $<$ http://portal.mec.gov.br/sesu/arquivos/pdf/130301Quimica.pdf $>$. Acesso em 10 ago 2014.

CHASSOT, A. Para que(m) é útil o ensino? 2ed. Canoas: ULBRA, 2004.

CORTINA, A.; MARTINEZ, E. Ética. Tradução, Silvana Cobucci Leite. São Paulo: Loyola, 2005.

ENCONTRO NACIONAL DE ENSINO DE QUÍMICA, XVI, 2012, Salvador. Anais eletrônicos. Salvador:NEHP/UFBA, 2012. Disponivel em: http://www.eneq2012.qui.ufba.br/. Acesso em 21 jul 2014.

ENCONTRO NACIONAL DE ENSINO DE QUÍMICA, XV, 2010, Brasília. Anais eletrônicos. Brasília:ADALTECH, 2010. Disponivel em:< http://www.xveneq2010.unb.br/> Acesso em 21 jul 2014.

ENCONTRO NACIONAL DE ENSINO DE QUÍMICA, XIV, 2008, Curitiba. Anais eletrônicos. Curitiba:UFPR/DQ, 2008. Disponivel em:< http://www.quimica.ufpr.br/eduquim/eneq2008/>. Acesso em 21 jul 2014.

GALLO, S. (Coord) Ética e Cidadania: Caminhos da filosofia. Grupo de Estudos sobre o Ensino de Filosofia. Campinas: Papirus, 15ed, 2003. 


\section{Educere Educare \\ ReVISTA DE EduCACÃ̃o}

Programa de Pós-Graduação em Educação - Universidade Estadual do Oeste do Paraná

LINS, M. J. S. C. et al. Avaliação da aprendizagem de ética em curso de formação de professores de Ensino Fundamental. Ensaio: aval.pol.públ.Educ., v. 15, n. 55,p. 255-276, jun. 2007.

NARDI, R. A pesquisa em Ensino de Ciências no Brasil: alguns recortes. In: Nardi, R. (Org) A área de Ensino de Ciências no Brasil: fatores que determinaram sua constituição e suas características segundo pesquisadores brasileiros. São Paulo: Escrituras, 2007;

OLIVEIRA, R. J. O ensino das ciências e a ética na escola: interfaces possíveis. Química Nova na Escola, n. 4, p.227-232, 2010.

PRADEL, C.; DÁU, J.A.T. A Educação para valores e as políticas públicas educacionais. Ensaio: aval.pol.públ.Educ., v. 17, n. 64, p. 521-548, jul-set. 2009.

RAZERA, J.C.C; NARDI, R. Ética no ensino de ciências: responsabilidades e compromissos com a evolução moral da criança nas discussões de assuntos controvertidos. Investigações em Ensino de Ciências, v.11, p. 53-66, 2006.

REVISTA QUÍMICA NOVA. Disponivel em: < http://quimicanova.sbq.org.br/>. Acesso em 20 jul 2014.

REVISTA QUÍMICA NOVA NA ESCOLA. Disponivel em: < http://qnesc.sbq.org.br/> Acesso em 22 jul 2014.

RIBEIRO, E. M. F.; MAIA, J. O.; WARTHA, E. J. As Questões Ambientais e a Química dos Sabões e Detergentes. Química Nova na Escola, n. 3, p. 169-175, 2010.

ROCHA FILHO, R. C. Ética da ciência: educação e difusão são imprescindiveis. Química Nova. v. 36, p.357, 2013.

SÁ, M. B. Z.; VICENTIN, E. M.; CARVAlHO, E. A História e a Arte Cênica como Recursos Pedagógicos para o Ensino de Química - Uma Questão interdisciplinar. Química Nova na Escola, n.1, p. 09-13, 2010.

TORRESI, S. I. C; PARDINI, V.L; FERREIRA, V.F. Ética nas publicações científicas. Química Nova. v. 31, p. 197, 2008.

2011.

Responsabilidade, ética e progresso social. Química Nova, v.34, p.1489, 


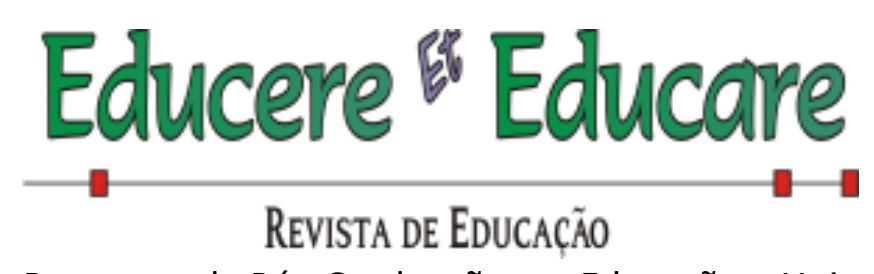

Programa de Pós-Graduação em Educação - Universidade Estadual do Oeste do Paraná

Recebido em: 07/06/2017

Aprovado em: 17/04/2018 